ANDRADE, G.M., MOURA, M.S. e ALMEIDA, L.P. Alternativas para nutrição em ovinos. PUBVET, Londrina, V. 5, N. 6, Ed. 153, Art. 1031, 2011.

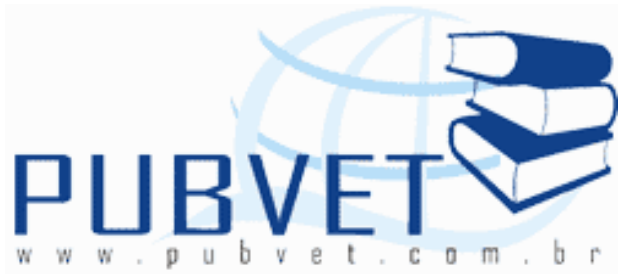

PUBVET, Publicações em Medicina Veterinária e Zootecnia.

\title{
Alternativas para nutrição em ovinos
}

Gabriella Mamede Andrade ${ }^{1 *}$, Mariela Silva Moura ${ }^{1}$, Laerte Pereira de Almeida ${ }^{2}$

${ }^{1}$ Graduanda em Medicina Veterinária, Universidade Federal de Uberlândia. Uberlândia, MG.

${ }^{2}$ Docente da Faculdade de Medicina Veterinária, Universidade Federal de Uberlândia. Uberlândia, MG.

*Autor para correspondência: Rua Ceará, s/n, Bloco 2D, CEP 38400-902, Uberlândia, MG, Brasil. E-mail: gabriellamamede@gmail.com

\section{Resumo}

A ovinocultura é uma atividade que vem se desenvolvendo em larga escala nos últimos anos no Brasil. A partir do momento que os ovinos passaram a apresentar um crescimento mais acelerado, maior ganho de peso, melhor conversão alimentar e maior rendimento de carcaça, suas exigências nas instalações, sanidades, cuidados, técnicas de manejo adequado cada vez crescem e com isso, a necessidade alimentar, a qual é tema desse trabalho, tornou-se consequentemente elevada. Alternativas para introduzir enriquecer ou mesmo substituir o alimento oferecido na ovinocultura vêm sendo cada vez mais estudadas, mostrando benefícios e malefícios de alguns compostos, tais como: farelo de glúten de milho que diminui a eficiência produtiva dos animais, reduzindo o ganho de peso e aumentando a conversão alimentar; a polpa de caju desidratada que é uma opção para amenizar os efeitos do período de seca 
ANDRADE, G.M., MOURA, M.S. e ALMEIDA, L.P. Alternativas para nutrição em ovinos. PUBVET, Londrina, V. 5, N. 6, Ed. 153, Art. 1031, 2011.

sobre os animais; o farelo de girassol que é uma alternativa para enriquecer e diminuir os custos da nutrição de ovinos em relação ao concentrado padrão; entre outros. É de suma importância garantir uma boa alimentação para que os animais possam desempenhar seu potencial ao máximo garantindo assim bons animais e melhores lucros no seu plantel.

Palavras-chave: alimentação alternativa, nutrição, ovinos.

\section{Alternatives for Sheep Nutrition}

\section{Abstract}

The sheep industry is an activity that has been developed on a large scale in recent years in Brazil. From the moment that the sheep began to exhibit faster growth, greater weight gain, feed conversion and higher carcass yield, their demands on the premises, sanity, health, appropriate management techniques increasingly grow and with it the need food, which is the subject of this work, therefore became high. Introduce alternatives to enrich or even replace the food offered in the sheep industry have been increasingly studied, showing advantages and disadvantages of some compounds, such as corn gluten meal which decreases the production efficiency of animals, reducing weight gain and increasing feed conversion, the cashew pulp is an option to mitigate the effects of drought on animals, sunflower meal that is an alternative to reduce costs and enhance the nutrition of sheep to the concentrate standard, among others. It is of utmost importance to ensure good nutrition for the animals can play their full potential thereby ensuring better profits and good animals in their breeding

Keywords: alternatives feeding, nutrition, sheep.

\section{Introdução}

A ovinocultura é uma atividade que vem se desenvolvendo em larga escala nos últimos anos no Brasil. Embora a atividade esteja crescendo, poucas são as fazendas realmente preparadas para essa prática, o que deve 
ANDRADE, G.M., MOURA, M.S. e ALMEIDA, L.P. Alternativas para nutrição em ovinos. PUBVET, Londrina, V. 5, N. 6, Ed. 153, Art. 1031, 2011.

ser mudado, pois essa atividade pode render ótimos lucros se a criação desses animais respeitarem suas necessidades, além de terem bons animais e se as condições ambientais, de manejo e alimentares forem adequadas.

A capacidade produtiva dos ovinos tem evoluído muito como fruto, principalmente, do melhoramento genético. Desde então seu mercado tem sido mais explorado e os produtos da ovinocultura mais valorizados.

A partir do momento que os ovinos passaram a apresentar um crescimento mais acelerado, maior ganho de peso, melhor conversão alimentar e maior rendimento de carcaça, suas exigências nas instalações, sanidades, cuidados, técnicas de manejo adequado cada vez crescem e com isso, a necessidade alimentar, a qual é tema desse trabalho, tornou-se conseqüentemente elevada.

As pesquisas sobre a substituição ou inclusão de produtos e subprodutos alternativos na alimentação animal tem se destacado no âmbito da nutrição animal.

Como os ovinos possuem limitada capacidade de consumir alimentos e possuem particularidades no processo de digestão e metabolização dos alimentos, essas novas exigências nutricionais nem sempre são atendidas e existem alguns nutrientes que podem tornar-se limitantes para que estes animais expressem todo seu potencial genético de produção de carne, lã, pele e leite principalmente quando se insistem em ficar apenas com os sistemas tradicionais de alimentação baseados quase que exclusivamente na pastagem natural.

Esta revisão bibliografia trará alternativas para introduzir, enriquecer ou mesmo substituir o alimento oferecido na ovinocultura, mostrando benefícios e malefícios de alguns compostos, tais como: farelo de glúten de milho, polpa de caju, farelo de girassol, silagem de milho e feno de aveia, dejetos de suínos entre outros.

Contudo é de extrema importância oferecer uma dieta alimentar que atenda a todas as exigências nutricionais dos animais, podendo, sim, escolher formas mais econômicas para introduzir a ração, pois embora possa aumentar 
ANDRADE, G.M., MOURA, M.S. e ALMEIDA, L.P. Alternativas para nutrição em ovinos. PUBVET, Londrina, V. 5, N. 6, Ed. 153, Art. 1031, 2011.

os custos da produção, a alimentação é à base de todo o sistema. Um rebanho mal nutrido além de apresentar queda na sua produção terá também, problemas de ordem produtiva e sanitária.

\section{Revisão de Literatura}

\section{Polpa de Caju}

Na ovinocultura, no regime extensivo da exploração, a principal fonte de alimentação é a pastagem nativa, a qual depende muito das condições climáticas da região que nem sempre são favoráveis, principalmente nas regiões onde é tradicional a criação de ovinos. Depender apenas da disponibilidade da pastagem é um fator que tem limitado o desenvolvimento zootécnico desta atividade, principalmente em relação à qualidade e quantidade dos produtos finais oferecidos ao consumidor (DANTAS et al.,2007).

Segundo Dantas et al.(2007), a polpa de caju desidratada é uma opção para amenizar os efeitos do período de seca sobre os animais.

Os experimentos mostraram que o ganho de peso obtido sem a introdução da polpa de caju desidratada foi superior na dieta com 30\% da polpa de caju desidratada, mas o tratamento com $30 \%$ de polpa de caju é amplamente favorável devido à diferença do custo total por quilograma de ração entre essas duas opções, portanto, para o ganho médio diário de ovinos em terminação, a polpa de caju desidratada pode ser incluída na dieta em níveis de até 30\% (nível que proporcionou o melhor retorno econômico). A inclusão de polpa de caju desidratada em rações para ovinos em terminação reduziu a retenção de nitrogênio e afetou negativamente a digestibilidade dos nutrientes (DANTAS et al., 2007).

\section{Alta proporção de concentrado e diferentes teores protéicos}

Muitas e diferentes recomendações foram vistas na literatura apontando a necessidade de uma maior averiguação das exigências protéicas de cordeiros 
ANDRADE, G.M., MOURA, M.S. e ALMEIDA, L.P. Alternativas para nutrição em ovinos. PUBVET, Londrina, V. 5, N. 6, Ed. 153, Art. 1031, 2011.

alimentados com alta quantidade de concentrado nas suas dietas (FERNANDES et al., 2005).

A otimização na utilização do nitrogênio dietético pelos ruminantes iniciase com a formulação da dieta, visando sua composição em termos de nitrogênio (proteína bruta), energia e outros nutrientes, além do seu comportamento no trato digestivo do animal em relação à sua digestibilidade, produção de ácidos graxos voláteis, síntese de proteína microbiana entre outros processos metabólicos (TEIXEIRA, 1996 apud FERNANDES et al., 2005,p.78).

Segundo trabalho de Teixeira et al. (2005) o teor de $16 \%$ de proteína bruta na dieta de ovinos em crescimento foi adequado, uma vez que valores elevados acabam originando perdas de N (Nitrogênio) através da urina. Dietas com alta proporção de concentrado $(80 \%)$, utilizando bagaço de cana-deaçúcar hidrolisado e in natura, proporcionaram um ambiente ruminal adequado, com valores de $\mathrm{pH}$ e concentrações de ácidos graxos voláteis satisfatórios.

\section{Pastagem de azevém}

O azevém passa por estádios fenológicos durante 0 ano, no desenvolvimento desses estádios verifica-se crescente acúmulo de colmos e material senescente no resíduo da pastagem o que determina diminuição na qualidade da dieta (PONTES et al., 2003 apud MEDEIROS et al., 2007). Diante desta restrição nutricional os animais desenvolvem diferentes estratégias de pastejo em adaptação à nova condição do ambiente de pastejo (MEDEIROS et al., 2007).

No trabalho realizado por Medeiros et al. (2007), com ovelhas em final de gestação e inicio de lactação para possibilitar um manejo mais eficiente que não permita que os índices de produtividade caiam, constataram-se que os maiores tempos de pastejo e consumos de matéria seca e proteína bruta ocorrem no final do período diurno para os estádios vegetativo, préflorescimento e de florescimento. Nos estádios iniciais, estes maiores valores 
ANDRADE, G.M., MOURA, M.S. e ALMEIDA, L.P. Alternativas para nutrição em ovinos. PUBVET, Londrina, V. 5, N. 6, Ed. 153, Art. 1031, 2011.

também ocorrem nos primeiros momentos de luz natural. No préflorescimento, em alta atividade de pastejo, as ovelhas elevam a taxa de bocados e a quantidade de forragem coletada por bocado e diminuem a qualidade do ingerido. No estádio de florescimento, reduz os tempos de pastejo e o consumo de matéria seca e de proteína bruta ao longo de todo o período diurno, como conseqüência da baixa qualidade da forragem disponível e da estrutura da vegetação.

\section{Farelo de glúten de milho}

Dentre as opções para se criar ovinos durante a seca em confinamento o farelo de glúten de milho surge como uma opção em que a produção é constante durante todo o ano. O principal fator limitante para o confinamento é o alto custo da alimentação, visto que, a utilização de dietas a base de milho e soja tem tornado o custo muito alto inviabilizando esta técnica (NEIVA et al., 2005).

O farelo de glúten de milho, um subproduto do processo do milho por via úmida, foi testado e incluído aos concentrados por Neiva et al. (2005) e foi observado que não altera o consumo de matéria seca em ovinos porém quanto mais colocar desse ingrediente nas rações diminui a eficiência produtiva dos animais, reduzindo o ganho de peso e aumentando a conversão alimentar. Por isso seu uso só deve ser indicado depois de uma delicada análise da relação custo/benefício, pois sua inclusão diminui a quantidade de farelo de soja e milho na dieta os quais são ingredientes que possuem relativamente altos custos.

\section{Dejetos de suínos}

A terminação de ovinos em confinamento é uma alternativa para intensificar a produção de carne nesses animais pois chega mais rápido ao peso de abate e o controle de verminoses é mais fácil. Como nessa prática os custos com alimentação são altos uma alternativa é usar dejetos de suínos, já que estes são produzidos em grandes quantidades na criação intensiva desses 
ANDRADE, G.M., MOURA, M.S. e ALMEIDA, L.P. Alternativas para nutrição em ovinos. PUBVET, Londrina, V. 5, N. 6, Ed. 153, Art. 1031, 2011.

animais, e também ajudará na preservação do meio ambiente (OLIVEIRA,1993 apud OLIVEIRA et al.,2003,p.1392).

No trabalho realizado por Oliveira et al. (2003) constatou que o uso de dejetos de suínos como parte da dieta, proporciona resultados satisfatórios no desenvolvimento de cordeiros terminados em confinamento, independente se $o$ dejeto seja do tipo denominado Bijú ou dejeto peneirado seco ao sol.

\section{Farelo de palma forrageira}

A busca por melhores resultados na pecuária é alcançada com o uso de concentrado, principalmente nas épocas em que as pastagens não suprem as necessidades nutricionais dos animais (VÉRAS et al., 2005).

Em um experimento que propôs a substituição do milho por farelo de palma forrageira na dieta de ovinos em crescimento Véras et al. (2005) observou que o farelo de palma forrageira não substitui o milho como fonte de energia para ovinos em crescimento. O coeficiente de digestibilidade dos nutrientes avaliados não apresentou resultado satisfatório com o aumento dos níveis de farelo de palma forrageira em substituição do milho.

\section{Farelo de girassol}

O Farelo de girassol surge como mais uma alternativa para enriquecer e diminuir os custos da nutrição de ovinos em relação ao concentrado padrão. $O$ farelo de girassol é um subproduto da industria de óleos vegetais (MICHAEL \& SUNDE, 1985 apud LOUVANDINI et al.,2007, p.603-604).

Louvandini et al. estudou níveis de substituição de 100 e $50 \%$ do farelo de soja pelo farelo de girassol no concentrado o que segundo eles proporcionou menor ritmo de crescimento e características de carcaças inferiores em ovinos Santa Inês em terminação, comprovando que estes níveis de substituição não são indicados para a categoria animal estudada. 
ANDRADE, G.M., MOURA, M.S. e ALMEIDA, L.P. Alternativas para nutrição em ovinos. PUBVET, Londrina, V. 5, N. 6, Ed. 153, Art. 1031, 2011.

\section{Silagem de capim elefante e farelo de cacau}

As diversas condições de alimentação podem modificar os parâmetros do comportamento ingestivo. A utilização de alimentos volumosos na alimentação de ruminantes é praticamente indispensável (CARVALHO et al., 2006).

Em um programa contínuo de alimentação de ovinos, caso haja disponibilidade, recomenda-se como alternativa alimentar o uso do farelo de cacau em substituição ao milho e farelo de soja em até $40 \%$ do concentrado ( $16 \%$ da dieta total). A amonização do capim elefante com $5 \%$ tem pouca influencia sobre o comportamento ingestivo de ovinos e quando superior a este valor promove maior tempo de ruminação (CARVALHO et al.,2006).

\section{Resíduo desidratado de vitinículas}

Os resíduos agroindustriais representam um recurso alimentar pouco explorado e passível de aproveitamento na alimentação de ruminantes (OLIVEIRA, 2003 apud BARROSO et al.,2006,p.1553).

O resíduo de vitinículas esta sendo desperdiçado na região do Vale do São Francisco, e pode ser aproveitado como suplemento na alimentação de ovinos garantindo um bom aporte de nutrientes para os animais (BARROSO et al.,2006).

A utilização do resíduo de vitinículas na alimentação de ovinos em terminação mostrou ser uma boa alternativa volumosa quando associada a diferentes fontes energéticas. As combinações do resíduo de vitinículas com o farelo de palma e com o grão de milho moído apresentaram bons desempenhos. A utilização deste resíduo pode trazer benefícios para a composição das dietas de pequenos ruminantes, principalmente na região do Vale do São Francisco, onde sua disponibilidade é fácil, podendo assim garantir maior disponibilidade de alimentos especialmente no período de escassez de forragem (BARROSO et al.,2006). 
ANDRADE, G.M., MOURA, M.S. e ALMEIDA, L.P. Alternativas para nutrição em ovinos. PUBVET, Londrina, V. 5, N. 6, Ed. 153, Art. 1031, 2011.

\section{Silagem de milho e feno de aveia}

Ribeiro et al. (2003) constatou os cordeiros que receberam como fonte volumosa a combinação de silagem de milho e feno de aveia apresentaram consumo de matéria seca superior se comparados com os animais que receberam exclusivamente silagem de milho ou feno de aveia como fonte de volumoso.

\section{Conclusão}

A nutrição dos ovinos, no sistema de criação, é responsável por uma alta parcela dos custos da produção. Como foi citado e explicado nesta revisão bibliográfica existem alternativas que podem mudar um pouco a composição do concentrado e que podem reduzir seu custo.

Além das opções que foram abordadas neste trabalho o produtor pode optar por outros suplementos de melhor acesso e disponibilidade em sua região.

O que é realmente importante é preservar o melhoramento genético em ovinos que tem evoluído e garantir uma boa alimentação para que os animais possam desempenhar seu potencial ao máximo garantindo assim bons animais e melhores lucros no seu plantel.

\section{Referências}

DANTAS, L. A. F.; LOPES, J. B.; VASCONCELOS, V. R.; OLIVEIRA, M. E. de; ALVES, A. A.; ARAÚJO, D. L. D. da C.; CONCEIÇÃO, W. L. F. Inclusão de polpa de caju desidratada na alimentação de ovinos: desempenho, digestibilidade e balanço de nitrogênio. Revista Brasileira de Zootecnia, v.36, n.1, p.147-154, 2007.

FERNANDES, M. H. M. R.; SUSIN, I.; PIRES, A. V.; FERNANDES, J. S. Jr.; FERNANDES, J. J. R. Metabolismo ruminal e digestibilidade de dietas com alta proporção de concentrado e diferentes teores protéicos para ovinos. ARS VETERINÁRIA, v.21, n.1, p.077-085, 2005.

MEdeiros, R. B. de; PEDROSO, C. E. da S.; JORNADA, J. B. J. da; SilvA, M. A. da; SAIBRO, J. C. de. Comportamento ingestivo de ovinos no período diurno em pastagem de azevém anual em diferentes estádios fenológicos. Revista Brasileira de Zootecnia, v.36, n.1, p.198$204,2007$.

NEIVA, J. N. M.; SOARES, A. N.; MORAES, S. A. de; CAVALCANTE, A. C. R.; LÔBO, R. N. B. Farelo de glúten de milho em dietas para ovinos em confinamento. Revista Ciência Agronômica, v.36, n.1, p.11-117, 2005. 
ANDRADE, G.M., MOURA, M.S. e ALMEIDA, L.P. Alternativas para nutrição em ovinos. PUBVET, Londrina, V. 5, N. 6, Ed. 153, Art. 1031, 2011.

OliveirA, M. V. M. de; PÉREZ, J. R. O.; GARCIA, I. F. F.; MARTINS, A. R. V. Desempenho de Cordeiros das Raças Bergamácia e Santa Inês, Terminados em Confinamento, Recebendo Dejetos de Suínos como Parte da Dieta. Revista Brasileira de Zootecnia, v. 32, n.6, p.1391$1396,2003$.

VÉRAS, R. M. L.; FERREIRA, M. de A.; VERÁS, A. S. C.; CARVALHO, F. F. R. de; CAVALCANTI, C. V. de A.; SANTOS, G. R. A.; MENDONÇA, S. de S.; SOARES, C. A.; SAMPAIO, C. B. Substituição do milho por farelo de palma forrageira em dietas para ovinos em crescimento, consumo e digestibilidade. Revista Brasileira de Zootecnia, v.34, n.1, p.351-356, 2005.

LOUVANDINI, H.; NUNES, G. A; GARCIA, J. A. S.; MCMANUS, C.; COSTA, D. M.; ARAUJO, S. C. de. Desempenho, características de carcaça e constituintes corporais de ovinos Santa Inês alimentados com farelo de girassol em substituição ao farelo de soja na dieta. Revista Brasileira de Zootecnia, v.36, n.3, p.603-609, 2007.

CARVALHO, G. G. P. de; PIRES, A. J. V.; SILVA, R. R.; VELOSO, C. M.; SILVA, H. G. de O. Comportamento ingestivo de ovinos alimentados com dietas compostas de silagem de capimelefante amonizada ou não e subprodutos agroindustriais. Revista Brasileira de Zootecnia, v.35, n.4, p.1805-1812, 2006 (supl.).

BARROSO, D. D.; ARAúJO, G. G. L. de; SILVA, D. S. da; GONZAGA, S. N.; MEDiNA, F. T. Desempenho de ovinos terminados em confinamento com resíduo desidratado de vitinículas associado a diferentes fontes energéticas. Ciência Rural, v.36, n.5, p.1553-1557, 2006.

RIBEIRO, E. L. de A.; ROCHA, M. A. da; MIZUBUTI, I. Y.; SILVA, L. das D. F. da; FISCHER, S. R.; SILVA, A. P. da. Desempenho de cordeiros desmamados aos 67 dias alimentados com silagem de milho e feno de aveia. Semina: Ciências Agrárias, v.24, n.1, p.85-92, 2003. 